\title{
Annualized Electricity Cost of Residential Solar PV System under Malaysia's NEM Scheme
}

\author{
Abdul Hafiz Razali ${ }^{1,2 *}$, Md Pauzi Abdullah ${ }^{1,2}$, Dalila Mat Said ${ }^{1,2}$ and Mohamad Yusri Hassan ${ }^{1,2}$ \\ ${ }^{1}$ Centre of Electrical Energy Systems (CEES), Institute of Future Energy (IFE), \\ Universiti Teknologi Malaysia, 81310 UTM Skudai, Johor, Malaysia. \\ ${ }^{2}$ School of Electrical Engineering, Faculty of Engineering Universiti Teknologi Malaysia, \\ 81310 UTM Skudai, Johor, Malaysia.
}

*Corresponding author: abdhafizr94@gmail.com

\begin{abstract}
Net energy metering (NEM) is a financial scheme that allows a consumer to generate, use and sell their excess energy to the grid. The main purpose of NEM is for self-consumption to reduce demand from the grid. It will allow customer to avoid being charged with expensive electricity tariff and hence reducing their monthly electricity bill. In other words, the annualized electricity cost could be reduced. NEM is commonly offered to residential solar photovoltaic (PV) system. Different PV size will determine the amount of energy that can be generated. This paper compares the annualized electricity cost of different residential customer types (large, medium and small) for different PV size under Malaysia's net energy metering (NEM) scheme. This paper utilizes the load profile and solar irradiation data for Malaysia. The results show that high PV size does not guarantee reduction in annualized electricity cost especially for medium customers as the excess PV generation can only be accumulated for 24 months. Large customers may have benefited the most with lower annualized cost with larger PV system, while small customers may not have benefited at all.
\end{abstract}

Keywords: Net energy metering, feed-in tariff, solar PV

(C) 2020 Penerbit UTM Press. All rights reserved

Article History: received 18 December 2019; accepted 15 April 2020; published 25 April 2020.

\section{INTRODUCTION}

Feed-in-Tariff (FIT) and Net Energy Metering (NEM) are two financial mechanisms used by many countries around the world to encourage renewable energy generation among residential customers. Most countries started with the FIT scheme where consumers receive payment from the utility for the amount of renewable energy they generate. The price they receive depends on the FIT price set by a country. In Malaysia, FIT was introduced in 2011 and the starting price for FIT is around RM 1.23 per $\mathrm{kWh}$ (up to and including $4 \mathrm{kWp}$ ) [1] of energy generated from solar PV. Residential customers can generate income by installing PV solar panel system at their home and selling it to the utility (such as TNB) and the customers will be paid monthly based on the amount of $\mathrm{kWh}$ generated by their PV system each month. They will receive this payment over a 21 years' contract period.

Although this FIT scheme is very attractive, it does require a huge financial cost for the utility to pay the PV owners. To cover the FIT cost, Malaysian government originally implemented a $1.0 \%$ and later, increased to $1.6 \%$ the tariff on electricity consumption [2]. This amount may need to be increased further if the FIT scheme continues. In 2016, the FIT scheme in Malaysia was discontinued and replaced with the NEM scheme.

Conceptually, NEM is a financial scheme for renewable energy owners, where they will be rewarded in terms of net $\mathrm{kWh}$ consumption not gross $\mathrm{kWh}$ generation. Net $\mathrm{kWh}$ consumption is defined here as the amount of $\mathrm{kWh}$ consumed minus the amount of $\mathrm{kWh}$ generated by the customer in one month. In other words, owners of renewable energy sources such as solar PV systems need to utilize the generated energy first. They were only being charged for the remaining energy supplied by the grid. Unlike FIT scheme, in NEM the utility does not pay for the $\mathrm{kWh}$ generated. However, solar PV owners are rewarded in a form of reduction in electricity bills due to the net metering concept. If the amount of $\mathrm{kWh}$ generated exceeds $\mathrm{kWh}$ consumption, the net generation will be carried over to the following month. This net generation can be carried over to next months for up to 24 months before it expires. If it remains unused for 24 months, the PV system owner will not receive any benefit from this net generation. Therefore, it can be said that under the NEM scheme, generating to much $\mathrm{kWh}$ may result in financial loss.

This paper will study the amount of financial returns that PV system owners can receive for different PV sizes. Three types of user will be used in the case study; large, medium and small. Existing electricity tariffs and NEM schemes for Malaysia will be used. This paper is organized as follows; the next section will discuss the NEM scheme and brief the NEM schemes introduced in various countries. The next section will present the data used for the case study. The financial returns for each PV size will be compared by using annualized electricity cost. The later section will present the results of the analysis. 


\section{NET ENERGY METERING (NEM)}

Net energy metering (NEM) has been introduced in 1983 in US. Different with FIT, the policy allows a consumer to generate, use and sell only the excess energy to the grid. The main objective of NEM is for self-consumption to reduce demand from the grid [3]. The policy requires the consumer to install the bidirectional meter. This net meter able to show the user are having excess or shortage of energy. If the meter rotate forward, means that the users are taping energy from the gird and rotate backward when users having excessing energy and import to the grid. Any excess generation after billing period will be given credits. These credit is used to offset the electricity bill [4]. The maximum roll over credits period is 12 or 24 months then the remaining credits either will be paid to customer or will be set to zero depends on country. Indirectly, the policy has made the grid act as a very huge storage [5].

NEM is seen as a new policy that covers many flaws from FIT policy. A well-designed NEM policy provides a simple, low cost, and easily administered way to deal with PV residential system. Since FIT requires a contract and two meters it will be more complex compared to NEM. Next is the factor of inflation. This phenomenon is very unpopular among FIT consumer since they experience the increasing of electricity rate only but not for the rate paid to them [6]. In NEM policy, it acts like a perfect hedge against rising electricity prices. Other than that, NEM policy able to reduce the power losses [7] by allowing the consumers consume the generated energy first and only export the excess energy instead of export all the generated energy like FIT policy that will cause the congested in transmission line and consequently caused the power losses.
However, NEM policy also have their limitations but still can be improved. Firstly, NEM takes longer for return of investment compared to FIT. The case in paper in [8] shows the NEM will takes 16.1 years compared to 11.5 years for FIT. Next, some places are implementing increasing-block rate tariff, which means the rate per $\mathrm{kWh}$ increases as the volume of consumption increases, will not necessarily mean a more profitable investment, especially for small consumers [7]. Finally, if the number of NEM consumers to be increased further, the utility revenue may be significantly reduced [7].

\subsection{NEM in Malaysia}

NEM was introduced in 2016 after looking at some improvements that can be made to FIT scheme. The NEM (NEM 2016) scheme is designed more ideal since the consumer can use the power generated first and then only sell the excess energy to the grid. However, in 2019, the government once again introduced a new NEM (NEM 2019) scheme with some improvements from the previous scheme.

For NEM 2016, solar energy is eligible for all type of consumer. For residential, the allowable capacity is up to $12 \mathrm{~kW}$ for single phase and $72 \mathrm{~kW}$ for three phases. While for commercial and industrial is up to $1 \mathrm{MW}$. The excess generation will be credited into next billing period at displaced cost. The maximum roll over period is 24 months and any surplus after 24 months will be forfeit [9].

\subsection{NEM in other countries}

Table 1 shows the details of NEM scheme for selected countries around the world.

Table 1. NEM schemes in other countries

\begin{tabular}{|c|c|c|c|c|}
\hline $\begin{array}{l}\text { Country/ } \\
\text { State }\end{array}$ & $\begin{array}{l}\text { Allowable } \\
\text { Technology }\end{array}$ & Allowable Customer & $\begin{array}{l}\text { Allowable } \\
\text { Capacity }\end{array}$ & $\begin{array}{l}\text { Net Excess Generation } \\
\text { (NEG) Rate Price }\end{array}$ \\
\hline $\begin{array}{l}\text { Australia/ } \\
\text { Queensland } \\
{[10]}\end{array}$ & Solar & $\begin{array}{l}\text { Households, } \\
\text { Small businesses } \\
\text { Consume less than } \\
100 \mathrm{MWh} \text { a year }\end{array}$ & $10 \mathrm{~kW}$ & $\begin{array}{l}\text { AUD } \$ 0.44 / \mathrm{kWh} \text { for excess } \\
\text { electricity exported to the } \\
\text { grid }\end{array}$ \\
\hline Cyprus [7] & Solar & Residential & $5.2 \mathrm{~kW}_{\mathrm{p}}$ & $\begin{array}{l}\text { Any remaining credits will } \\
\text { be set to zero. No payment } \\
\text { to the consumer for energy } \\
\text { excess }\end{array}$ \\
\hline Greece [11] & $\begin{array}{l}\text { PV, small wind } \\
\text { power plants, } \\
\text { biomass, biogas, } \\
\text { small hydro and } \\
\text { CHP }\end{array}$ & All customer classes & $\begin{array}{l}\mathrm{PV}-20 \mathrm{~kW} \\
100 \mathrm{~kW}_{\mathrm{p}}\end{array}$ & $\begin{array}{l}\text { After a year, any remaining } \\
\text { credits will be set to zero. } \\
\text { No payment to the } \\
\text { consumer for energy excess. } \\
{[30]}\end{array}$ \\
\hline $\begin{array}{l}\text { Netherlands } \\
{[12]}\end{array}$ & $\begin{array}{l}\text { Solar, wind, } \\
\text { hydropower, } \\
\text { geothermal, } \\
\text { biomass }\end{array}$ & $\begin{array}{l}\text { Residential, } \\
\text { commercial, industrial }\end{array}$ & $\leq 500 \mathrm{~kW}$ & $\begin{array}{l}\text { Any remaining credits will } \\
\text { be set to zero. No payment } \\
\text { to the consumer for energy } \\
\text { excess }\end{array}$ \\
\hline
\end{tabular}


Generally, most countries have higher sell rates of net excess generation rate price compared to Malaysia, since the price of sell rates are reflected from retail rates of electricity.

\section{CASE STUDY}

This section will be explained about the data will be used in case studies.

\subsection{Residential Load Profile, Solar Output for Malaysia}

The residential consumer has more specific trend for load profile, since most people work on office hours and not much different of lifestyle. The overall trend will be low at midnight until early morning since most of them are sleeping. Then, the trend become medium on early morning until late evening, time the people going to work. At night, the trend will be higher since the people are resting and spend time with family. Therefore, one load profile trend has been chosen to use for the research which reflect the average residents load profile specifically in Malaysia [13]. From the original trend, the graph was modified to develop three different residential consumption sizes, small, medium and large which are consume $300 \mathrm{kWh}, 600 \mathrm{kWh}$ and $900 \mathrm{kWh}$ per month respectively. The load profile for small, medium and large residents as shown in figure 1 . Assume that all types of resident will produce same load profile for every day.

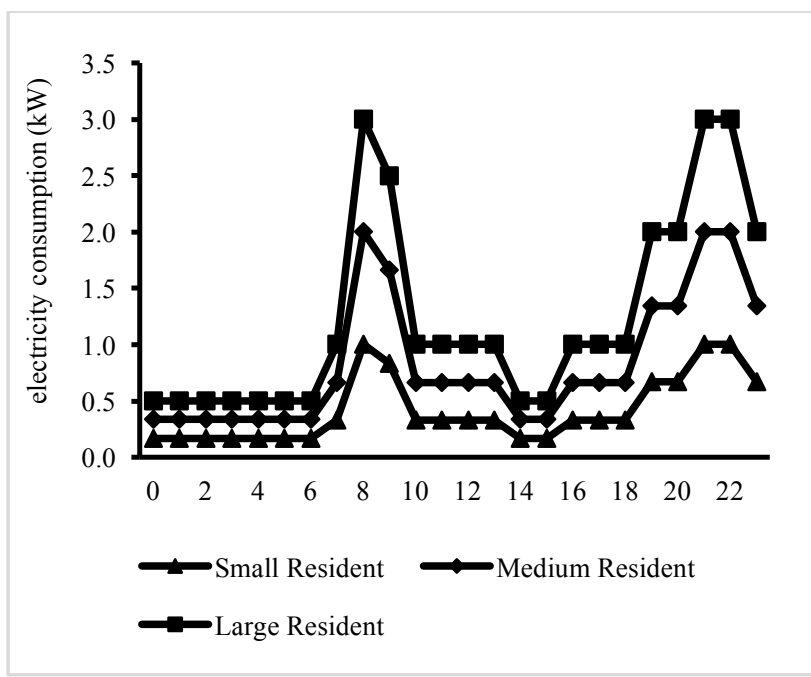

Figure 1. Energy Consumption for Different Size of Residents

Malaysia as a tropical country, receive sunlight more consistently throughout the year. Figure 2 shows the PV output for the daily PV output trends for $2 \mathrm{kWp}, 4 \mathrm{kWp}$, $6 \mathrm{kWp}$ and $8 \mathrm{kWp}$, which is based on $1 \mathrm{kWp}$ PV panel presented in $[14,15]$. In this paper, it is assumed that every day the PV output will be the same. Therefore, daily PV output for $2 \mathrm{kWp}, 4 \mathrm{kWp}, 6 \mathrm{kWp}$ and $8 \mathrm{kWp}$ are $7.08 \mathrm{kWh}$, $14.16 \mathrm{kWh}, 21.24 \mathrm{kWh}$ and $28.32 \mathrm{kWh}$ per day. The details as shown in table 2 .

Next, the capital costs of PV panels for $2 \mathrm{kWp}, 4 \mathrm{kWp}$, $6 \mathrm{kWp}$ and $8 \mathrm{kWp}$ are RM 13,900, RM 26,000, RM 35,000 and RM 42,000 respectively [16]. While the maintenance costs are RM 150, RM 200, RM 250 and RM 300 respectively. The detail as shown in table 3 .

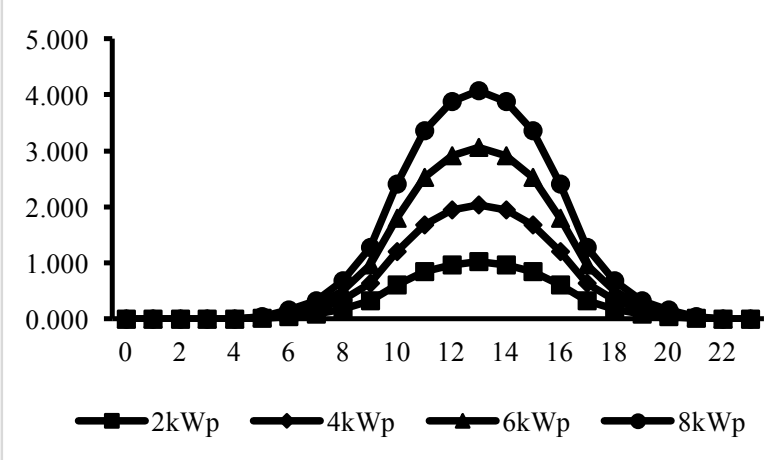

Figure 2. Daily PV Output for Different Size of PV Panels

Table 2. Daily PV output for different PV panel size

\begin{tabular}{|c|c|c|c|c|c|c|}
\hline \multirow{2}{*}{ Time } & \multicolumn{6}{|c|}{ PV Output } \\
\hline & $1 \mathrm{~kW}$ & $2 \mathrm{~kW}$ & $4 \mathrm{~kW}$ & $6 \mathrm{~kW}$ & $8 \mathrm{~kW}$ & $12 \mathrm{~kW}$ \\
\hline 0 & 0.000 & 0.000 & 0.000 & 0.000 & 0.000 & 0.000 \\
\hline 1 & 0.000 & 0.000 & 0.000 & 0.000 & 0.000 & 0.000 \\
\hline 2 & 0.000 & 0.000 & 0.000 & 0.000 & 0.000 & 0.000 \\
\hline 3 & 0.000 & 0.000 & 0.000 & 0.000 & 0.000 & 0.000 \\
\hline 4 & 0.000 & 0.000 & 0.000 & 0.000 & 0.000 & 0.000 \\
\hline 5 & 0.005 & 0.010 & 0.020 & 0.030 & 0.040 & 0.060 \\
\hline 6 & 0.020 & 0.040 & 0.080 & 0.120 & 0.160 & 0.240 \\
\hline 7 & 0.040 & 0.080 & 0.160 & 0.240 & 0.320 & 0.480 \\
\hline 8 & 0.085 & 0.170 & 0.340 & 0.510 & 0.680 & 1.020 \\
\hline 9 & 0.160 & 0.320 & 0.640 & 0.960 & 1.280 & 1.920 \\
\hline 10 & 0.300 & 0.600 & 1.200 & 1.800 & 2.400 & 3.600 \\
\hline 11 & 0.420 & 0.840 & 1.680 & 2.520 & 3.360 & 5.040 \\
\hline 12 & 0.485 & 0.970 & 1.940 & 2.910 & 3.880 & 5.820 \\
\hline 13 & 0.510 & 1.020 & 2.040 & 3.060 & 4.080 & 6.120 \\
\hline 14 & 0.485 & 0.970 & 1.940 & 2.910 & 3.880 & 5.820 \\
\hline 15 & 0.420 & 0.840 & 1.680 & 2.520 & 3.360 & 5.040 \\
\hline 16 & 0.300 & 0.600 & 1.200 & 1.800 & 2.400 & 3.600 \\
\hline 17 & 0.160 & 0.320 & 0.640 & 0.960 & 1.280 & 1.920 \\
\hline 18 & 0.085 & 0.170 & 0.340 & 0.510 & 0.680 & 1.020 \\
\hline 19 & 0.040 & 0.080 & 0.160 & 0.240 & 0.320 & 0.480 \\
\hline 20 & 0.020 & 0.040 & 0.080 & 0.120 & 0.160 & 0.240 \\
\hline 21 & 0.005 & 0.010 & 0.020 & 0.030 & 0.040 & 0.060 \\
\hline 22 & 0.000 & 0.000 & 0.000 & 0.000 & 0.000 & 0.000 \\
\hline 23 & 0.000 & 0.000 & 0.000 & 0.000 & 0.000 & 0.000 \\
\hline Total & 3.540 & 7.080 & 14.160 & 21.240 & 28.320 & 42.480 \\
\hline
\end{tabular}

\subsection{Annualized cost}

Two basic economic concepts will be used in this research to value the cost saving for 25 years period. The two concepts are net present cost (NPC) and annualized cost. NPC is the present value of all the costs the system incurs over its lifetime, minus the present value of all the revenue it earns over its lifetime [17]. While, annualized cost of the component is the cost that, if it were to occur equally in 
every year of the project lifetime, would give the same net present cost as the actual cash flow sequence associated with that component [18]. The formulas of both economic concepts are shown below:

$$
\begin{aligned}
& N P C=\left(\sum_{t=1}^{N} \frac{R_{t}}{(1+i)^{t}}\right) \\
& \text { Annual worth }=\text { present value } \times \frac{i(1+i)^{N}}{(1+i)^{N}-1}
\end{aligned}
$$

Where;

$$
\begin{aligned}
& R_{t} \text { - net cash flow } \\
& \mathrm{i}-\text { real discount rate } \\
& \mathrm{N} \text { - number of years } \\
& \mathrm{t} \text { - time cash flow }
\end{aligned}
$$

This paper uses real discount rate, $i$ of $6 \%$, and assumes that every year it will produce the same value. While, the project lifetime, $\mathrm{N}$, is set for 25 years. Therefore, the simplified formula is written as:

$$
\begin{aligned}
& N P C=\left(\sum_{t=1}^{25} \frac{R_{t}}{(1.06)^{t}}\right) \\
& \text { Annual worth }=\text { present value } \times \frac{0.06(1+0.06)^{25}}{(1+0.06)^{25}-1}
\end{aligned}
$$

Table 3. Capital and Maintenance Cost for Different Size of PV Panels

\begin{tabular}{|c|c|c|}
\hline $\begin{array}{c}\text { PV Panel Size } \\
\left(\mathrm{kW}_{\mathrm{p}}\right)\end{array}$ & $\begin{array}{c}\text { Initial Capital } \\
(\mathrm{RM})\end{array}$ & $\begin{array}{c}\text { Maintenance } \\
\text { Cost }(\mathrm{RM})\end{array}$ \\
\hline 2 & 13,900 & 150 \\
\hline 4 & 26,000 & 200 \\
\hline 6 & 35,000 & 250 \\
\hline 8 & 42,000 & 300 \\
\hline
\end{tabular}

\subsection{Electricity tariff}

The electricity tariff used in this paper is based on TNB Tariff A - domestic tariff on residential consumer.The electricity bill is calculated monthly by multiplying the total consumption in a month with Tariff A. Then, it is assumed that monthly electricity bill is the same for every month, then the annual electricity bill is calculated as follows;

$$
\left(\sum_{d=1}^{30} \sum_{h=1}^{24} P_{d, h}^{\text {consump }}\right) \times \text { Price } \text { tariff }^{\text {ta }} 12
$$

Since the electricity bill is calculated for 25 years, the present cost is considered. Assume that the discounted value is $6 \%$ every year. The total electricity bill for 25 years can be formulated as follows;

$$
\begin{array}{r}
\sum_{n=1}^{25}\left(\sum_{d=1}^{30} \sum_{h=1}^{24} P_{d, h}^{\text {consump }} \times \text { Price } e^{\text {tariff }} \times 12\right) \times \\
\frac{1}{1.06^{n-1}}
\end{array}
$$

$$
\begin{aligned}
& \text { Cost }_{\text {existing }}^{\text {annualized }}=\sum_{n=1}^{25}\left[\left(\sum_{d=1}^{30} \sum_{h=1}^{24} P_{d, h}^{\text {consump }}\right) \times\right. \\
& \text { Price } \left.e^{\text {tariff }} \times 12\right] \times \frac{1}{1.06^{n-1}} \times 78.227 \times 10^{-3}
\end{aligned}
$$

\section{RESULTS AND ANALYSIS}

The results for large, medium and small customers for different PV size is given in figure 3, 4 and 5 respectively. From figure 3, for large customers, the higher the PV size, the lower the annualized electricity cost. The cost is maximum if the large customer didn't install solar PV system and reduces as the size of solar PV system increases. In this study, large customer consumes $900 \mathrm{kWh}$ a month. They are paying the high electricity tariff at 21.8 cents $/ \mathrm{kWh}$ (for $1-200 \mathrm{kWh}$ ), 33.4 cents $/ \mathrm{kWh}$ (for 201-300 $\mathrm{kWh}$ ), 51.6 cents $/ \mathrm{kWh}$ (for 301-600 kWh) and 54.6 cents/kWh (for 601-900 kWh). With solar PV system, the customer can generate its own energy and reduce the amount of energy bought from the utility (TNB). With this, the customer can avoid paying the high electricity tariff. The bigger the PV size, more energy can be generated resulting in lower electricity bill and hence lower annualized cost.

Figure 4 shows the results for medium customers. The annualized electricity cost is reducing from No PV into 4 $\mathrm{kWp}$ PV size, slightly reduces for $6 \mathrm{kWp} \mathrm{PV} \mathrm{size} \mathrm{but}$ increases for $8 \mathrm{kWp}$ PV size. These results show that bigger PV size $(8 \mathrm{kWp})$ will not benefit PV owner as it consumes lower kWh energy than large customer. It will only result in high net generation that can only be carried over to next months for up to 24 months. If PV generation is higher than $\mathrm{kWh}$ consumption for every month, the net generation will not give any financial benefit.

From Figure 5, it can be seen that the small customers with no PV systems has the lowest annualized electricity cost. The cost increases as the PV size increases. In this case study, small customer only consumes $300 \mathrm{kWh}$ a month and hence only being charged with low electricity tariff at 21.8 cents $/ \mathrm{kWh}$ (for $1-200 \mathrm{kWh}$ ) and 33.4 cents/kWh (for 201-300 kWh). Any PV generation will not benefit small customers as they already paying low electricity bill. Having PV system will only increase the electricity cost due to high capital cost of PV system.

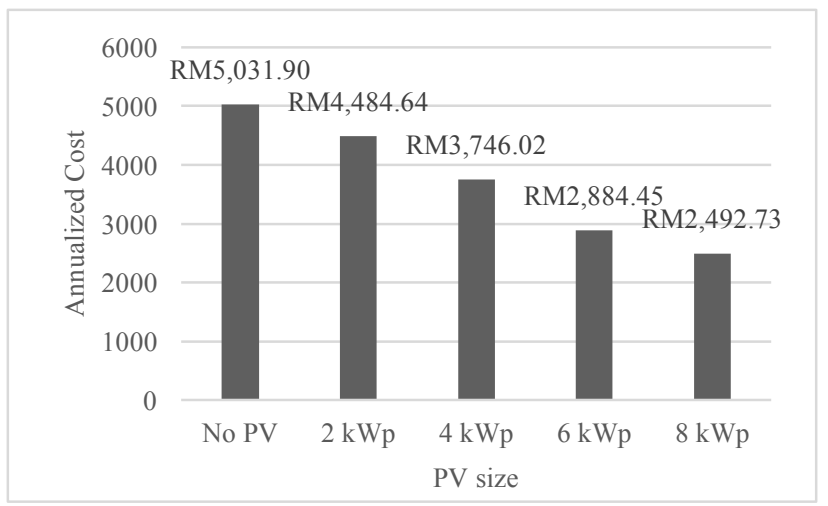

Figure 3. Annualized cost for large customer for different PV sizes

Therefore, the annualized cost of can be formulated as follows; 


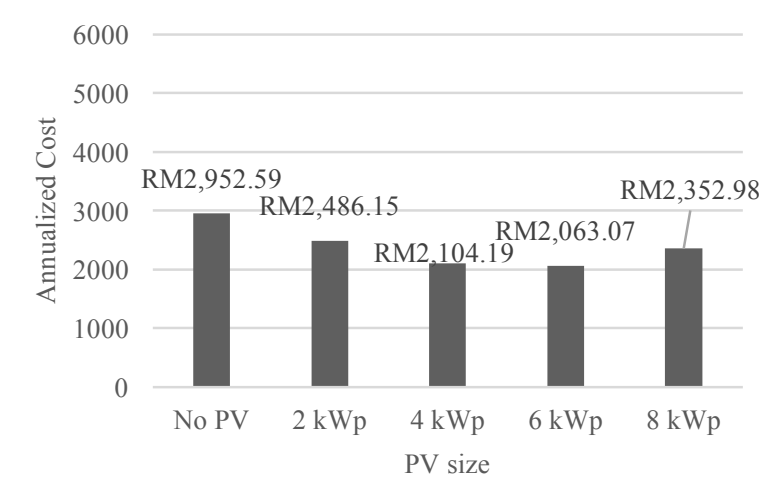

Figure 4. Annualized cost for medium customer for different PV sizes

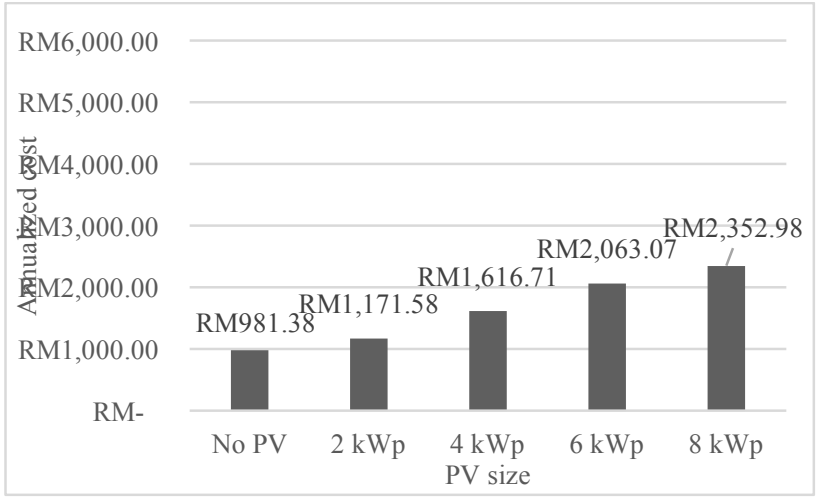

Figure 5. Annualized cost for small customer for different PV sizes

\section{CONCLUSION}

This paper compares the annualized electricity cost of different residential customers for different PV size system under net energy metering (NEM) scheme. The results show that high PV size does not guarantee reduction in annualized electricity cost especially for medium customers as the excess PV generation can only be accumulated for 24 months. Large $\mathrm{kWh}$ consumers may have benefited the most with lower annualized cost with larger PV system, while small customers do not benefited at all as the annualized cost for all sizes are higher than the system without PV.

\section{REFERENCES}

[1] Abdul Rahman, Hasimah \& Wan Omar, Wan Zaidi \& Nor, K.M. \& Hassan, Mohammad Yusri \& Majid, Mdshah. (2012). Feed-in Tariffs for BIPV system: A Study of Malaysia Government Building. Archives des Sciences -Geneve-. 65. 1661-464X.

[2] Pacudan R., P. H. (2014). Electricity Price Impacts of Feed-in Tariff Policies: The Cases of Malaysia, the Philippines, and Thailand. ERIA Research , 283319.

[3] Oh, T.H., et al., Energy policy and alternative energy in Malaysia: Issues and challenges for sustainable growth - An update. Renewable and Sustainable Energy Reviews, 2018. 81(Part 2): p. 3021-3031.

[4] Poullikkas, A., G. Kourtis, and I. Hadjipaschalis, A review of net metering mechanism for electricity renewable energy sources. International Journal of Energy \& Environment, 2013. 4(6).

[5] Christoforidis, G.C., et al. Assessing policies for photovoltaic net-metering in Greece. IET Conference Proceedings, 2014. 24 (8 .)-24 (8 .).

[6] Bakhtyar, B., et al., Potentials and challenges in implementing feed-in tariff policy in Indonesia and the Philippines. Energy Policy, 2013. 60: p. 418-423.

[7] Nikolaidis, A.I. and C.A. Charalambous, Hidden financial implications of the net energy metering practice in an isolated power system: Critical review and policy insights. Renewable and Sustainable Energy Reviews, 2017. 77: p. 706-717.

[8] Tan, R.H.G. and T.L. Chow, A Comparative Study of Feed in Tariff and Net Metering for UCSI University North Wing Campus with $100 \mathrm{~kW}$ Solar Photovoltaic System. Energy Procedia, 2016. 100(Supplement C): p. 86-91.

[9] Sustainable Energy Development Authority of Malaysia. Guidelines of Solar Photovoltaic Installation on NEM Scheme. [cited 2017 Oct. 5, 2017]; Available from: http://seda.gov.my.

[10] Zahedi, A., A review on feed-in tariff in Australia, what it is now and what it should be. Renewable and Sustainable Energy Reviews, 2010. 14(9): p. 32523255.

[11] Christoforidis, G., et al., A Model for the Assessment of Different Net-Metering Policies. Energies, 2016. 9(4): p. 262.

[12] Net Metering Program. [cited 2017 11/10/2017]; Available from: https:/www.hollandbpw.com/myhome/rates-and-programs/programs/net-meteringprogram.

[13] Ponniran, A., N.A. Mamat, and A. Joret, Electricity profile study for domestic and commercial sectors. International Journal of Integrated Engineering, 2012. 4(3).

[14] Solar Panel Output Calculator. [cited 2019 8//12/2019]; Available from: https://solarpanelsvenue.com/solar-panel-outputcalculator/.

[15] Average Solar Radiation. [cited 2019 8/12/2019]; Available from: https:/www.pveducation.org/pvc drom/properties-of-sunlight/average-solarradiation\#.

[16] GSPARX. Residential Solar Plan. [cited 2019 8/12/2019]; Available from: www.gsparx.com.

[17] HOMER ENERGY. Total Net Present Cost. [cited 2019 Jan. 23, 2019]; Available from: https://www.homerenergy.com/products/pro/docs/3. 11/total_net_present_cost.html.

[18] HOMER ENERGY. Annualized Cost. [cited 2019 8/12/2019]; Available from: https://www.homerenergy.com/products/pro/docs/la test/annualized_cost.html 